Journal of English Language Teaching and Applied Linguistics

ISSN: 2707-756X

DOI: $10.32996 /$ jeltal

Journal Homepage: www.al-kindipublisher.com/index.php/jeltal

JELTAL

\title{
A Comparative Analysis of Traditional Flipping Versus Virtual Flipping
}

\author{
Asiya Tabassum 8 (D) \\ English Language Center, University of Technology and Applied sciences, Nizwa, Oman \\ $\triangle$ Corresponding Author: Asiya Tabassum, E-mail: asiya.tabassum@nct.edu.om
}

\author{
ARTICLE INFORMATION \\ Received: March 11, 2021 \\ Accepted: April 25, 2021 \\ Volume: 3 \\ Issue: 4 \\ DOI: $10.32996 /$ jeltal.2021.3.4.8
}

\section{KEYWORDS}

Flipped classroom approach, traditional flipped classroom, virtual flipped classroom, Writing skills, student-centered approach

\section{ABSTRACT}

Flipped classroom approach is the most sought after neoteric pedagogical approach in the present times. This approach is clinching prodigious recognition as it employs a blend of techniques and technologies. The present study compared flipping a traditional class and a virtual class. The study aims to weigh the effects of flipping writing skills course in a traditional class and virtual class on the performance, attitudes and perceptions of English Language Learners'. The research used a quasiexperimental design with pre-test and post-test with a control group. The group consisted of 24 English language learners attending the level four foundations program at Nizwa College of Technology. The same group was given instructions by flipping traditional class for 3 weeks and virtual class for 3 weeks. Independent and paired sample t-tests were implemented for interpreting the pre-test and post-test data. The results showed a statistically significant difference between the writing skills course's traditional flip and virtual flip. It was evident that the students in traditional flip surpassed the students in virtual flip in performance. Students in both modes showed positive attitudes towards the approach. This study would benefit educators in Oman in general and at NCT, particularly in adapting a very effective approach that would help them improve students' performance by involving them and making them responsible for their learning. The limitations of the study were absenteeism, limited sample size. There was also a little reluctance from students towards this approach. Studies on flipped classroom approach in language learning classrooms are limited, but studies on flipping a virtual class are even more limited. Very few researchers investigated the impact of flipping a virtual class. More research is needed in this aspect. More long-term research is needed with different skills and a larger sample size to uncover the efficacy of flipping both traditional and virtual class.

\section{Introduction}

The education system is undergoing a spellbinding transformation with the advent of technology. Learning in the present times is not confined to only educational settings. It can happen anytime and anywhere. Educators all over the globe are hunting for and embracing new technological tools in their teaching practice. The learning approaches and preferences have changed largely due to these technologically advanced teaching tools. These tools are going on proliferating and are being acknowledged by the teachers. The majority of the educators in the present times are looking for supplementing new teaching practices leaving behind traditional teaching methods. Recently, there was a call for educators globally to transmogrify the learners into digital instigators of knowledge (Alexander et al., 2017). In response to such calls to incorporate technology into the classroom in order to instil 21 $1^{\text {st }}$-century skills in learners (Alexander et al., 2017; Bennett \& Lemoine, 2014; Johnson, 2009), flipped classroom approach received recognition. This approach has made possible the shift of classroom instructions from teacher-centred to student-centred. (Hwang, Lai \& Wang, 2015; Al Rowais, 2016; Gayathri \& Vijayarani, 2017; Sivarajah, Curci, Johnson, Lam, Lee \& Richardson, 2018). Although many studies have been conducted to notice the potency of this approach in teaching EFL students. The generality of these studies concentrated on observing the effectiveness of the traditional flipped

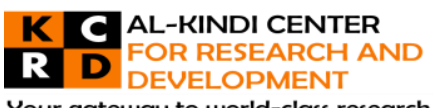

Your gateway to world-class research

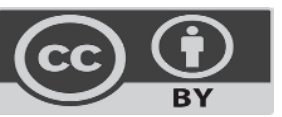

Published by Al-Kindi Center for Research and Development, United Kingdom. Copyright (c) the author(s). This open access article is distributed under a Creative Commons Attribution (CC-BY) 4.0 license 
classroom approach. Research on its efficacy on EFL students' performance, attitudes, and perceptions on virtual flipping remains scarce.

\subsection{Research purpose}

This specific study aims to answer the following research questions:

1. What is the effect of traditional flipping on the writing skills of Omani EFL students?

2. How Omani EFL students perceive the virtual flipping of the writing skills class?

\subsection{Significance of the Research}

The significance of the research is represented by providing the students with a new learning environment in both face-to-face instructions and online instructions. Furthermore, flipped classroom approach augments learning interactions, enhance students' performance and help inculcate $21^{\text {st }}$ century skills. Studies show that it invigorates students' interest and positively affects their attitudes towards education. Traditional flipping (TF) and Virtual flipping (VF) will increase students' motivation. Moreover, it provides opportunities to facilitate learning.

\section{Literature Review}

\subsection{Flipped classroom Model}

This new approach was first broached by two high school chemistry teachers, Jonathan Bergmann and Aaron Sams, in 2006. This new instructional method enables the educators to effectively using their class time as it flips the role of teacher and students in and outside the classroom. In flipped classroom students are no more passive listeners of lectures; instead, they actively participate in the classroom activities. (Baepler, Walker \& Driessen, 2014; Davies, Dean \& Ball, 2013; O'Flaherty \& Phillips, 2015). This approach demands students to watch pre-recorded video lectures provided by the teacher at home before coming to the class. Students have the freedom to pause, play, and replay the videos as many times, as they want and whenever they have time. Students can simultaneously take notes of the important points by pausing the video. When they come to class, they already know the content and therefore, the class time can be effectively utilized to engage them in active learning either in groups or individually. The teacher in the entire situation is a mere facilitator like a "guide on the side." The teacher can provide constructive feedback while monitoring students work. Students get individualized support from the teacher and immediate help is available to them whenever needed.

This approach is called flipped as it flips the traditional classroom lecturing part from classwork to pre-class work, and the traditional home task of applying the learned content in the form of homework is done in the classroom. Due to this flip, students get immediate feedback and support from teachers while applying the concepts taught (Anderson, 2012). Flipped classroom approach is a form of instructional strategy and a type of blended learning that facilitates access to information for students in order to acquire the most satisfaction by making students actively involved in the learning process. (Anderson, 2012, as cited in Ekmekci, 2014, p. 56-57).

Flipped classroom approach reinforces the flaws of the traditional approach and therefore gained notable attention. This novel approach offers solutions to the possible problems in traditional education. The quintessential part of this approach is its shift of focus from teacher-centred to student-centred. Students' role in the flipped classroom changes from passive listeners to active participants and it makes learners responsible of their own learning.

This concept can be applied in varied forms in the higher education system. The two types of flipped which are considered for the present study are as follows:

\subsection{Traditional flipping}

This is the standard format; students in this flip prepare themselves before the class by doing the pre-class work assigned by the teacher. The pre-class work can be watching video lectures, reading materials etc., In class, the students apply the concepts, whether collaboratively or individually and receive personalized feedback from the teacher at the same time after the class; students review what they learned.

\subsection{Virtual flipping}

In this type of flip, classroom time can be eliminated completely. Lectures in the form of videos are shared for students' viewing. Students are assigned tasks and these are collected via online learning management systems. The students can seek teachers help during office hours for brief one to one session based on their individual needs. During the sessions, teacher plays a passive role in encouraging students.

In order to flip a class, be it traditional flipping or virtual flipping, the instructor must adhere to the four pillars of the flipped classroom: Flexible learning environment, Learning culture, intentional content and professional educator (Bauer-ramazani et al., 
2016). Here learning Environment suggests physical location, and it must be flexible in time and place. Learning culture denotes a shift in the instructional approach from teacher-centred to student-centred. Intentional content indicates that the focus of this approach is the development of students' vocational or cognitive skills. At the same time, professional educators prioritize the role of an educator in designing materials for pre-class work and also the role of teacher during the class in facilitating learning and providing feedback (Mcnally et al., 2017).

The current study on the flipped classroom approach elucidated the strengths and drawbacks of traditional flipping and virtual flipping. Traditional flipping allows the teacher to expend class time more productively in observing students' work, giving them personalized feedback and assessing their work (Marshall and DeCapua (2013). According to Carhill-Poza (2019), teachers employing flipped approach can assimilate collaborative learning. Arifani (2019) added that the learners' collaboration could be improved by incorporating the approach. It also stimulates higher-order thinking skills, as claimed by (Bergmann \& Sams, 2012; Bishop \& Verleger, 2013). On the other hand, virtual flipping allows the teachers and students to interact through a variety of communication channels like audio, video, virtual whiteboards, etc. Virtual flipping enables both synchronous and asynchronous interaction between learners and educators. This synchronized virtual learning environment boosts learners' satisfaction (Thomson, 2010) and provides opportunities for a student-teacher, student-student and student-content interactions, and helps in obtaining immediate feedback (Allmendinger, Kempf \& Hamann, 2009; Lietzau \& Mann, 2009). However, the asynchronous situation of virtual flipping empowers students to participate in class activities at their own pace and time. It also solves problems of students who miss their real-time classes.

Some technologies that can be adopted by the educators while flipping the virtual classroom includes sending personal messages through WhatsApp, collaborative White-board, Moodle and email for materials sharing, Near pod, H5p for PowerPoint presentations and doing real-time surveys with students, Zoom breakout rooms to divide students into groups for collaborative activities. Apps like Google Meet and Zoom for recording online sessions and meeting students in urgent needs for one-one sessions. The recorded lectures can be uploaded to Moodle, Edpuzzle or google drive for students to watch later.

\section{Methodology}

\subsection{Subjects}

The current study was carried on with a sample size of 24 students, 10 females and 14 males. The age of the participants ranged between 20-22 years. All the students studied foundation program level 4 at the English language center, Nizwa College of Technology. Studying foundations levels are a pre-requisite to study specialization courses.

\subsubsection{Context}

Nizwa College of Technology is one of the seven colleges of technology under the Ministry of manpower in Oman. The college offers bachelors' degree in Business, Information Technology and Accounting. Before registering for the specialization programs, the students have to enrol for the foundation program to be trained in English language skills, IT skills, Study skills and Mathematics skills. The English foundation program consists of four levels. The English language center follows the IELTS format to train and test students'.

\subsection{Instrument}

\subsubsection{Achievement test}

The researcher developed the pre-test and post-test questionnaires and EFL writing test after traditional flipping and virtual flipping. The English language center uses IELTS rubrics at NCT to mark students' tests, so the same was used by the researcher to mark the pre-test and post-test to obtain the results and find the efficacy of the traditional flipping and virtual flipping. The researcher used "Edpuzzle" for traditional flipping and email, google meet and Moodle for virtual flipping. Although the English language center at NCT is well equipped with Moodle LMS, the researcher chose an additional online platform, "Edpuzzle" for traditional flipping so that student's performance can be tracked keenly, whereas, for the virtual flipping, the researcher opted for the LMS Moodle as it was easily available for the all the students. All the students who participated in the study own a mobile phone with an internet connection and has laptops with Wi-Fi connection at home to access the materials sent to them before class time.

\subsubsection{Student interviews}

A semi-structured interview was conducted to determine students' perception of the flipped classroom approach. Primary data was also collected from in-class observations and classroom survey questionnaire. The qualitative interviews were used as they enable in-depth research opportunities. For this purpose, a sample of students was selected randomly. The responses from interviews and questionnaires helped determine students" perception, attitudes and efficacy of the flipped classroom approach and their preferences about traditional flipping and virtual flipping. 


\subsubsection{Questionnaire}

The questionnaires were designed to measure students' preference towards traditional flipping and virtual flipping. Moreover, to measure their overall attitude towards this novel approach. The questionnaire comprises of 10 questions using five-points--Likert format: (5) strongly Agree (SA), (4) Agree (A), (3) Neither Agree or Nor Disagree (NA), (2) Disagree (DA), (1) Strongly Disagree (SD). The responses were collected by personally distributing the questionnaires to students. This Data collection helped the researcher in knowing about the efficacy of the traditional flipping and virtual flipping in particular students' attitudes and perception towards the flipped classroom approach in general.

\subsection{Data collection procedure}

The present research was conducted by employing a quasi-experimental design. The researcher implemented a one group pretest and post-test design to uncover the effect of traditional flipping and virtual flipping on the writing skills of Omani EFL students. Pre-test and post-test designs are the most preferred method to compare participants and evaluate the proportion of change after implementing the research.

\subsubsection{Online learning platforms}

The researcher used two different platforms for traditional and virtual flipping.

\section{Learning platform used for traditional flipping}

The researcher flipped the traditional class with a flipped class for three weeks by employing the user-friendly interface "Edpuzzle." It is a platform designed to aid teachers in enhancing and encouraging students' involvement and ameliorating their knowledge using video lessons. The teachers can record and upload the videos or use the videos available on the Edpuzzle site. The application is free, easy to download and work with. The available videos on site are from khan academy, zillion and YouTube. The teachers are free to decide whether they want to share their own videos or videos available on the site. In case the teachers wanted to self-record and share, they cannot make any changes to these videos. However, if they choose videos from the site, they can crop the videos, voice-over, and embed the quiz in between the video. The application gives a detailed report of students' activity.

\section{Learning platforms used for virtual flipping}

The researcher flipped the class virtually for another 3 weeks. The platforms used for this flip were "Google meet" and "canvas." Google meet is an effective remote learning platform and the best alternative to a physical classroom. On the other hand, Canvas is a web-based LMS it aids educators and students in accessing and managing their courses online. The canvas used for this research was free and can be easily accessed by the students. The teacher posted the videos to discuss canvas. The video was posted in parts to get enough practice and understanding of each part of the essay. Each video student was prompted to discuss a question that would help understand the writing explained in the video.

\section{Flipped classroom videos}

The researcher developed six videos based on the traditional and virtual flipped classroom topics. Research was carried out in order to find the best suitable materials for the chosen topics. There were many videos available on YouTube; some of them were used as extra materials to be shared with students but a lot of them had complex language which would be difficult for the students to understand; hence, it was decided to make interactive PowerPoints and to use that PowerPoints videos were recorded using Apowersoft screen recorder with teachers' voice. The final video was shared with students through google drive as they are comfortable using the drive.

\subsection{Data Analysis procedure}

The research was carried out mainly to scrutinize the students' viewpoint on the traditional flipped classroom in comparison to virtual flipped classroom for their writing classes. The data conducted was analyzed using SPSS (Statistical Package for the Social Sciences) program. The average of the tests after the traditional flip and virtual flip were employed to evaluate the achievement level of the participants in this study.

\section{Results}

The test scores manifest that the mean score of the traditional flipping before the virtual flipping was 23.37 with a standard deviation of 3.987. While the mean score after the virtual flipping was 21.50 with a standard deviation of 4.55 .

\begin{tabular}{|l|l|l|l|l|l|}
\hline \multicolumn{7}{|c|}{ Paired samples statistics } \\
\hline & & Mean & N & Std.Deviation & Std. Error Mean \\
\hline \multirow{3}{*}{ Pair 1 } & Pre-test & 23.3750 & 24 & 3.98707 & .81386 \\
\cline { 2 - 6 } & Post-test & 21.5000 & 24 & 4.55879 & .93056 \\
\hline
\end{tabular}




\section{Paired Samples Test}

\begin{tabular}{|c|c|c|c|c|c|c|c|c|c|}
\hline & \multicolumn{5}{|c|}{ Paired Differences } & \multirow[t]{3}{*}{$\mathrm{t}$} & \multirow[t]{3}{*}{$d f$} & \multirow{3}{*}{$\begin{array}{l}\text { Sig. (2- } \\
\text { tailed) }\end{array}$} \\
\hline & & \multirow[t]{2}{*}{ Mean } & \multirow[t]{2}{*}{$\begin{array}{l}\text { Std. } \\
\text { Deviation }\end{array}$} & \multirow[t]{2}{*}{$\begin{array}{l}\text { Std. Error } \\
\text { Mean }\end{array}$} & \multicolumn{2}{|c|}{ 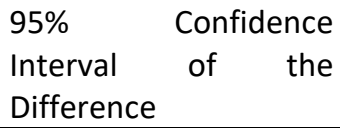 } & & & \\
\hline & & & & & Lower & Upper & & & \\
\hline Pair 1 & $\begin{array}{l}\text { Scores on } \\
\text { test } \\
\text { traditional } \\
\text { flipping- } \\
\text { scores on } \\
\text { test } \\
\text { virtual } \\
\text { flipping }\end{array}$ & 1.87500 & 4.09997 & .83690 & 14373 & 3.60627 & 2.240 & 23 & .035 \\
\hline
\end{tabular}

A paired sample test was administered to compare traditional flipping and virtual flipping. The results indicate a significant difference in the scores $(t)=2.240, P=0.035$. It can be concluded from the results that students perceived traditional flipping to be beneficial; however, they showed a negative response towards virtual flipping.

\section{Discussion and Conclusion}

This research study compared students' viewpoints in traditional flipped classroom vs virtual flipped classroom. The study's findings revealed that the scores of students after the traditional flip were better than that after the virtual flip. The results of the virtual flipped classroom could be attributed to the factor as reported in an interview by almost all the students that they did not get to meet the teacher in person after watching the videos to clarify their doubts and students were not able to work in pairs and groups as they did in the traditional flip. They missed that presence of the teacher, although they met the teacher and peers virtually via google meet. Students also reported that internet connection was the issue when they were attending virtual classes. Students lost interest in in-class activities due to a lack of physical activity. Many students complained of inefficiency in using the computers and demanded an extra training session. Another major challenge for the teacher while adopting the virtual flipped approach was that the teacher could not ask students to switch on their cameras due to cultural restraints. As a result, the teacher could not observe the students and students also feel that there is a lack of belongingness. There was no proper learning atmosphere and students miss that lack of real-time teaching experience. As a result, of all these drawbacks, the student could only learn through the videos posted by the teacher without getting much opportunity to interact face to face with the teacher and peers.

The results of traditional flip indicated that the traditional flipped approach had a positive impact on students learning. The traditional flip supports the previous research that flipped classroom helped students understand the concept better and proliferate students' writing competency. It also made students' accountable for their learning. Moreover, it provides an opportunity for the students to work at their own pace anytime, anywhere. However, it initially adds to the workload of the teacher. The feedback collected after the traditional flipped classroom approach from students by distributing questionnaires and conducting interviews and the post-test results unfolded that traditional flipped classroom as a positive approach.

There are some limitations to this study, which needs serious consideration. The main limitation is the research methodology; this research was carried out using a quasi-experimental research design and with only pre-recorded video lessons. One more limitation was the cultural restraints, due to which the teacher could not see the students attending the virtual session as it was not allowed to ask students to keep their cameras on during the sessions.

Despite the limitation of methodology, sample size and cultural constrain, the study yielded the pedagogical differences between traditional flip and virtual flip. The study recommends conducting a similar study with all boys or all girls' groups and the research could be conducted for the whole semester to see the effectiveness of the approach. Overall, it can be concluded that the results of this study are not meant to be generalized because it was conducted with small sample size and for a concise duration and there was a cultural hindrance involved. 


\section{Acknowledgements}

The author expresses the most profound appreciation to the Dean Nizwa College of Technology and the Head of the Center English Language center at Nizwa College of technology to conduct the research and gather data. The researcher would also like to thank the colleagues who helped in the research.

Funding: This research received no external funding.

Conflicts of Interest: The author declares no conflict of interest.

About the Author: Ms. Asiya Tabassum has been working as a lecturer at the University of Technology and Applied sciences, Nizwa, Oman, for eight years. She did her masters from Osmania University, Hyderabad, India. In addition, she received a certificate for a course in TESOL from American Training Institute, Kerala, India. Her research interests are using education technologies and experimenting with writing skills using different platforms.

\section{References}

[1] Alexander, M. (2018). The Flipped Classroom: Engaging the Student in Active Learning. Journal Of Legal Studies Education, 35(2), 277-300. doi: 10.1111/jlse.12078

[2] Allmendinger, K., Kempf, F., \& Hamann, K. (2009). Collaborative Learning in Virtual Classroom Scenarios. Lecture Notes in Computer Science Learning in the Synergy of Multiple Disciplines, 344-349. doi:10.1007/978-3-642-04636-0_33

[3] Arifani, Y. (2019). The application of small group and individual flipped model with WhatsApp to foster EFL learners' cohesive writing skill. Library Hi Tech News, 36(4), 10-12. doi:10.1108/lhtn-12-2018-0075

[4] Baepler, P., Walker, J. D., \& Driessen, M. (2014). It's not about seat time: Blending, flipping, and efficiency in active learning classrooms. Computers and Education, 78, 227-236. https://doi.org/10.1016/j.compedu.2014.06.006

[5] Bauer-Ramazani, C., Graney, J. M., Marshall, H. W., \& Sabieh, C. (2016). Flipped Learning in TESOL: Definitions, Approaches, and Implementation. TESOL Journal, 7(2), 429-437. doi:10.1002/tesj.250

[6] Bennett, N., \& Lemoine, G. (2014). What a difference a word makes: Understanding threats to performance in a VUCA world. Business Horizons, 57(3), 311-317. doi: 10.1016/j.bushor.2014.01.001

[7] Bishop, J., \& Verleger, M. (n.d.). The Flipped Classroom: A Survey of the Research. 2013 ASEE Annual Conference \& Exposition Proceedings. doi:10.18260/1-2-22585

[8] Carhill-Poza, A. (2019). Defining flipped learning for English learners in an urban secondary school. Bilingual Research Journal, 42(1), 90104. doi:10.1080/15235882.2018.1561552

[9] Davies, R., Dean, D., \& Ball, N. (2021). Flipping the Classroom and Instructional Technology Integration in a College-Level Information Systems Spreadsheet Course. Retrieved 20 April 2021, from https://papers.ssrn.com/sol3/papers.cfm?abstract id =2321828

[10] EKMEKCI, E. (2017). THE FLIPPED WRITING CLASSROOM IN TURKISH EFL CONTEXT: A COMPARATIVE STUDY ON A NEW MODEL. Turkish Online Journal Of Distance Education, 151-151. doi: 10.17718/tojde.306566

[11] Galindo, I. (2014). Flip Your Classroom: Reach Every Student in Every Class Every Day. By Jonathan Bergmann and Aaron Sams. Alexandria, Va.: The Association for Supervision and Curriculum Development, 2012. ix 112 pages. ISBN 978-1-56484-315-9. \$13.57. Teaching Theology \& Religion, 17(1), 82-83. doi:10.1111/teth.12165

[12] H, G. (2021). Effectiveness Of Flipped Classroom Strategies On Enhancing Learning Performance Of Chemistry And In Certain Selected Variables Among The Students Of Standard Xi. Retrieved 20 April 2021, from https://shodhganga.inflibnet.ac.in/jspui/handle/10603/299926

[13] Hwang, G., Lai, C., \& Wang, S. (2015). Seamless flipped learning: a mobile technology-enhanced flipped classroom with effective learning strategies. Journal Of Computers In Education, 2(4), 449-473. doi: 10.1007/s40692-015-0043-0

[14] Lietzau, J. A., \& Mann, B. J. (2009). Breaking out of the Asynchronous Box: Using Web Conferencing in Distance Learning. Journal of Library \& Information Services in Distance Learning, 3(3-4), 108-119. doi:10.1080/15332900903375291

[15] McNally, B., Chipperfield, J., Dorsett, P., Del Fabbro, L., Frommolt, V., \& Goetz, S. et al. (2016). Flipped classroom experiences: student preferences and flip strategy in a higher education context. Higher Education, 73(2), 281-298. doi: 10.1007/s10734-016-0014-z

[16] O'Flaherty, J., \& Phillips, C. (2021). The use of flipped classrooms in higher education: A scoping review. Retrieved 20 April 2021, from (2021). Retrieved 20 April 2021, from https://files.eric.ed.gov/fulltext/EJ1145315.pdf

[17] (2021). Retrieved 20 April 2021, from http://infonomics-society.org/wp-content/uploads/ijcdse/published-papers/special-issue-volume-42014/The-Impact-of-Flipped-Learning-on-Achievement-and-Attitudes-In-Higher-Education.pdf

[18] Saad ALRowais, A. (2014). The Impact of Flipped Learning on Achievement and Attitudes In Higher Education. International Journal For Cross-Disciplinary Subjects In Education, 4(Special 1), 1914-1921. doi: 10.20533/ijcdse.2042.6364.2014.0266

[19] Says:, C. B. (2017, July 11). Flipping in the Virtual Education World. Retrieved from https://flippedlearning.org/flexible_environment/flipping-virtual-education-world/

[20] Singer, L. M., \& Alexander, P. A. (2017). Reading on Paper and Digitally: What the Past Decades of Empirical Research Reveal. Review of Educational Research, 87(6), 1007-1041. doi:10.3102/0034654317722961

[21] Sivarajah RT, Curci NE, Johnson EM, Lam DL, Lee JT, Richardson ML. (2019). A Review of Innovative Teaching Methods. Acad Radiol. Jan;26(1):101-113. doi: 10.1016/j.acra.2018.03.025. Epub 2018 May 9. PMID: 30929697.

[22] Thomson, D. L. (2010). Beyond the Classroom Walls: Teachers and Students Perspectives on How Online Learning Can Meet the Needs of Gifted Students. Journal of Advanced Academics, 21(4), 662-712. doi:10.1177/1932202x1002100405 